\title{
Effect of Deep Cryogenic Pre-treatment for Substrates on Mechanical Property of DLC Films
}

\author{
Xiaoling Gong ${ }^{\mathrm{a}}$, Chaoyin $\mathrm{Nie}^{\mathrm{b}^{*}}$, Qiu Jin ${ }^{\mathrm{c}}$, Yang Zhou ${ }^{\mathrm{d}}$ and Yanzhong Nie \\ Faculty of Materials and Energy, Southwest University, Chongqing 400715, China \\ agx1920802@163.com, bniecy@swu.edu.cn, cautumn1@email.swu.edu.cn, \\ dzy712520@email.swu.edu.cn, ${ }^{d} 1208604514 @ q q . c o m$
}

\begin{abstract}
Key words: DLC films; deep cryogenic pre-treatment; bonding strength; friction property; interface optimization.

Abstract: $2 \mu \mathrm{m}$ thick DLC multilayer films were deposited on W9 high-speed steel with deep cryogenic pre-treatment (DCT) for 30 hours in liquid nitrogen by unbalanced magnetron sputtering technique, which were compared with the DLC films without DCT. The results show that compound systems with DCT exhibit higher film-substrate bonding strength and superior friction wear property, which are closely related to the DCT effect that martensitic transformation and decomposition, grain refinement and carbides precipitation. Thus the hardness, strength and residual stress of substrate are improved remarkably, and deformation compatibility between film and substrate under external load become more coordinating. Meanwhile, surface morphology of substrate is effectively adjusted by phase transformation, as a result, element diffusion and mechanical interlocking effect of film-substrate interface are optimized with added grain boundary and fine uniform organization.
\end{abstract}

\section{Introduction}

Diamond-like Carbon (DLC) films, a kind of fascinating materials, having some features of both graphite and diamond, such as high hardness, good wear resistance, low friction coefficient, chemical inertness and biocompatibility, which have been extensively used in many fields due to its excellent properties [1-4]. However, high residual compressive stress and weak adhesion of DLC films to substrate has restricted their working life and applications [5-6]. To reduce the residual stress and to enhance the adhesion and mechanical properties of DLC films, a lot of techniques have been studied by researchers [7-11], such as changing sedimentary means, doping third elements $(\mathrm{N}, \mathrm{Cr}, \mathrm{Ti}, \mathrm{W}$, etc), incorporating metal transition layer. Nonetheless, previous studies have their own limitations because these ways focus primarily on changing the properties of films.

Deep cryogenic treatment is a special kind of heat treatment technology, and has been efficiently performed on metal materials since 1940. Samples are cooled down in liquid nitrogen for some periods, then gradually warmed up to room temperature, which is used regularly after quenching and before tempering. A lot of studies suggest that DCT allows the occurrence of phase transition and microstructure refinement, it can significantly improve some properties of metal substrate [12-14]. From previous studies, we believe that the hardness, strength and surface state of metallic substrates are equally important for bonding strength and properties of films [15-16]. In this paper, deep cryogenic treatment was used to improve the properties of metallic substrates. we mainly investigated the mechanical property of DLC films from film-substrate bonding strength and friction performance. Moreover, the effect of DCT on microstructure and surface state of substrates were significantly discussed as well as the optimization mechanism of film-substrate interface.

\section{Experimental}

2.1 High-speed steel DCT and DLC films deposition. Quenched high-speed steel W9Mo3Cr4V in size of $15 \mathrm{~mm} \times 12 \mathrm{~mm} \times 2 \mathrm{~mm}$ was selected as substrate material. The chemical constituent of high-speed steel W9Mo3Cr4V is listed in Table 1. Substrate material was divided into group a and 
group b after grinded and polished. Our previous experiments show that W9 high-speed steel in liquid nitrogen for 30 hours exhibits excellent integrated mechanical properties including hardness, strength and fracture resistance. So group b was DCT for 30 hours, and group a was untreated. Furthermore, in order to investigate stress variation of substrate in deposition processing, a part of samples were simulated for deposition temperature: were insulated in temperature of $160^{\circ} \mathrm{C}$ environment for 4.5 hours.

Table 1 Chemical constituent of high-speed steel W9Mo3Cr4V

\begin{tabular}{cccccccc}
\hline $\mathrm{C}$ & $\mathrm{W}$ & $\mathrm{Mo}$ & $\mathrm{Cr}$ & $\mathrm{V}$ & $\mathrm{Si}$ & $\mathrm{Mn}$ & $\mathrm{S}, \mathrm{P}$ \\
\hline $0.77-0.87$ & $8.50-9.50$ & $2.70-3.30$ & $3.80-4.40$ & $1.30-1.70$ & $0.20-0.40$ & $0.20-0.40$ & $\leq 0.03$ \\
\hline
\end{tabular}

Unbalanced magnetron sputtering technique was adopted to deposit DLC films on polished high-speed steel substrates that had been ultrasonically cleaned in acetone and anhydrous ethanol respectively for 10 minutes. Magnetron sputtering deposition device of Shenyang scientific instrumental LD600 type was used for the deposition with solid graphite target and acetylene as C source. During the process of deposition, intermediate layers of $\mathrm{Cr}$ and $\mathrm{Cr} / \mathrm{C}$ were sequentially introduced. Afterwards, film's thickness of all samples were controlled at about $2 \mu \mathrm{m}$ by adjusting deposition time. For this purpose, films-forming temperature is about $160^{\circ} \mathrm{C}$ and deposition time is about $4.5 \mathrm{~h}$. Detailed deposition procedure was found in our previous report [17]. Processing flow of high-speed steel substrates in this study is shown in Fig.1.

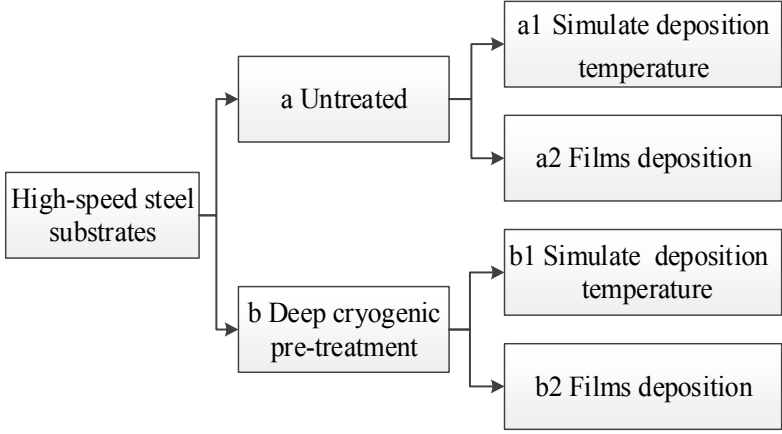

Fig.1 Processing flow of high-speed steel substrates

2.2 Films and substrates characterization. The cross-section morphology and surface topography of DLC films were observed by SEM (JSM-6610) and AFM (CSPM-5500). The film-substrate bonding strength was qualitatively inspected by using Rockwell hardness tester (HR-150A) with $1471 \mathrm{~N}$ for 10 seconds. The ball-disc friction and wear tester, produced by Swiss CSM company, was applied to friction and wear experiments. The wear test parameters were as follows: diameter of 304 stainless steel ball was $6 \mathrm{~mm}$, axial load was $2 \mathrm{~N}$, sliding distance was 200m, sliding speed was $6 \mathrm{~mm} / \mathrm{s}$. Then, FESEM (JSM-6700F) and 3D laser microscope test (OLS4000) were used to observe the wear scars and their sectional contour. Metallographic microscope was applied to observing metallographic structure of high-speed steel. Besides substrates a, b, a1, b1 in fig.1, the surface residual stress of substrates a2, b2 were measured by XRD (Bruker D8 DISCOVER). Because penetrating depth of X-ray is dozens of microns, which is far more than the thickness of DLC films, so it can roughly judge the effect of DCT on residual stress of substrate a2, b2.

\section{Results and discussion}

3.1 Structure of DLC films. Cross-section morphology of DLC films is shown in Fig.2 (a), it can clearly see that DLC films have three layers which combine well without obvious pores, from top to bottom respectively are DLC layer, $\mathrm{Cr} / \mathrm{C}$ gradient layer and $\mathrm{Cr}$ transition layer, total thickness is about 2 microns. The unconformity and difference of thermal expansion coefficient between DLC films and substrates can be reduced by transition layer and gradient layer, thus inner stress of films is decreased and film-substrate bonding strength is improved to some extent. Fig.2 (b) shows the surface 3D topography of DLC films with $3000 \mathrm{~nm} \times 3000 \mathrm{~nm}$ of measure area, the average surface roughness and the size of maximum height of film respectively are $5.69 \mathrm{~nm}, 55.99 \mathrm{~nm}$. DLC films in 
this study were deposited in a low-temperature condition and thermal no-equilibrium state, and their surfaces exhibit three-dimensional cauliflowers structure that are agglomerated by $\mathrm{C}$ atoms clusters [18]. In addition, some microscopic bumps and holes are randomly arranged in surface region, but there is no obvious defect.

\section{(a)}

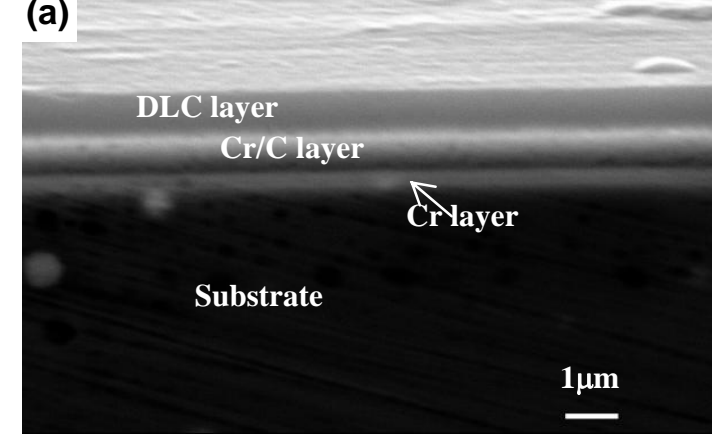

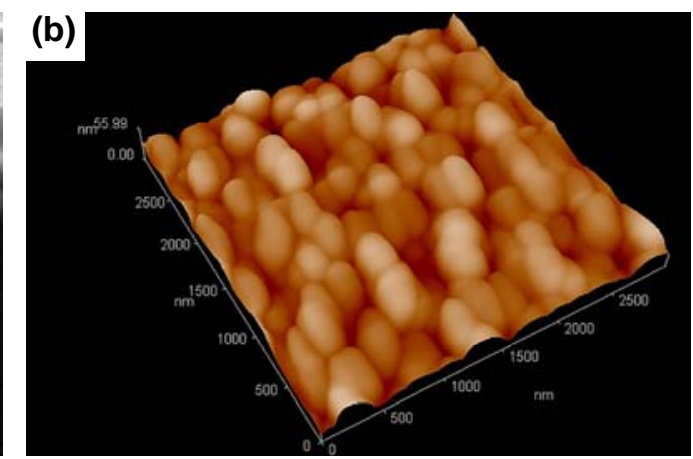

Fig.2 Cross-sectional morphology (a) and surface 3D topography (b) of DLC films

3.2 Film-substrate bonding strength of DLC films. Film-substrate bonding strength of DLC films are qualitatively evaluated in accordance with the damage made by Rockwell hardness tester. As seen in Fig.3, lots of white matter is obviously seen around indentation edge of untreated DLC films, the continuous and comparative inerratic shedding occurs along the entire indentation circumference. Besides, it can be found that plaques are square shape instead of round or bar. Nevertheless, in comparison, shedding of DLC films with DCT around indentation circumference becomes intermittent, white matter and crack density of indentation are significantly reduced at the same time. Delamination and failure of films are closely related to the deformation compatibility and interface bonding strength between films and substrates. During the process of unloading, great elastic-plastic mismatch and high residual stress will be generated in film-substrate interface with poor deformation coordination, which leads to delamination of films. Moreover, shedding of plaques occurs on the edge of indentation because shear stress here is the largest. Shedding forming is affected by crack at the same time, square shape is mainly because of meshing formation effect of radial cracks and circumferential cracks [19].

As seen in Fig.4, there are a few coarse acicular martensites and partial residual austenites in untreated substrate, And white undissolved alloy carbide that in block or granule presents uneven distribution. At low temperature of DCT, the structure contraction and a different expansion coefficient of martensite and austenite cause a high degree of stress, which force carbon atoms to jump to grain boundaries, so carbide particle size is decreased and carbide distribution becomes more uniform. Transformation and decomposition of martensite bring refinement of grain and increase of grain boundary to substrate [13-14]. On the one hand, greater contact areas of film and substrate due to the refine grains and new homogeneous carbides will provide more places to nucleation at the beginning of films deposition, and mechanical interlocking of interface will be enhanced in its favor. On the other hand, added grain boundaries will offer more channels for atoms diffusion to composite systems as well as new locations to intergranular segregation[20]. What's more, deformation compatibility of film and substrate becomes more coordinating due to the improvement of hardness, strength and toughness, it can reduce concentration of stress. So DLC films with DCT exhibit superior film-substrate bonding strength. 

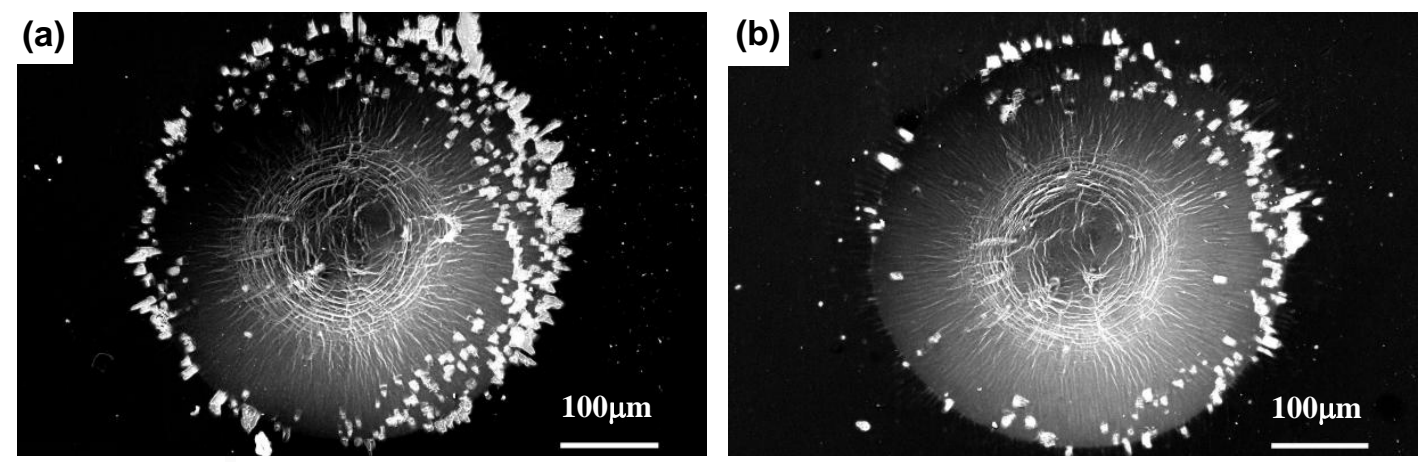

Fig.3 SEM image of Rockwell indentation of DLC films (a) Untreated; (b) DCT

\section{(a)}

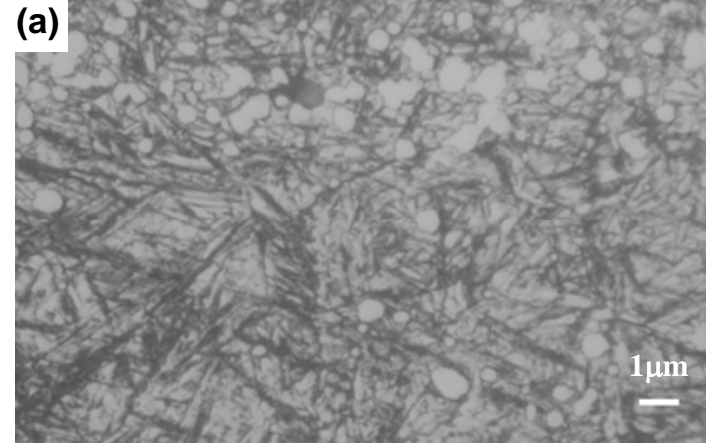

(b)

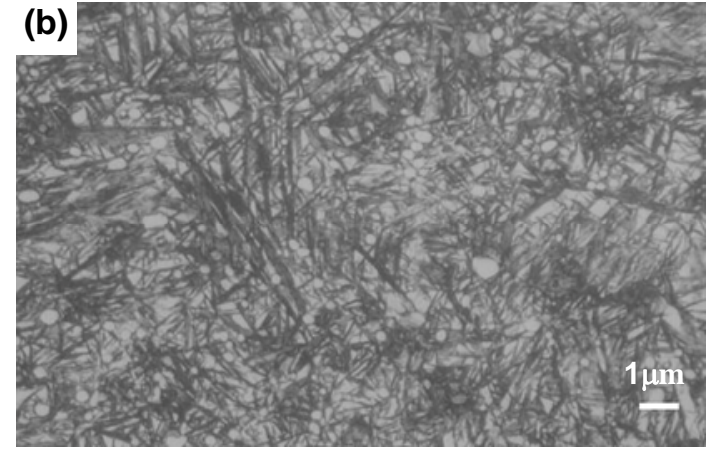

Fig.4 micrograph of high-speed steel at 1000× (a) Untreated; (b) DCT

3.3 Friction wear property of DLC films. Morphology and sectional contour of DLC films'wear scar are respectively shown in Fig.5 and Fig.6. It can be seen that both two groups of DLC films aren't worn out and failure only occurs within DLC layers. The untreated DLC films suffered heavily damage with obvious furrow, width of wear scar is about $200 \mu \mathrm{m}$, while depth is about $0.8 \mu \mathrm{m}$. Conversely, wear scar of DLC film with DCT is flat and smooth, the width and depth respectively are about $100 \mu \mathrm{m}, 0.25 \mu \mathrm{m}$. The wear rate of films is reduced obviously through DCT, and the wear resistance of DLC films improved remarkably. Wear resistance and lifetime of DLC films are thus ruled by its capacity to handle through thickness cracks and interfacial failure [21], just as the improvement of bonding strength that has been discussed in section 2.2 will promote wear resistance of DLC films. Additionally, wear resistance is influenced by load-bearing capacity of substrate.

As listed in Table 2, residual stress of untreated substrate before deposition is $-369.20 \mathrm{MPa}$, and the substrate through DCT is up to $-446.02 \mathrm{MPa}$. The high degree of added residual compress stress is mainly because of different expansion coefficient of grains in liquid nitrogen. Film deposition temperature has equal effect of low temperature tempering for substrate. Not only can it improve hardness and wear resistance, but it can reduce internal stress and brittleness of substrate. The surface residual stress of two groups both are close to $-290 \mathrm{MPa}$. It shows that the final residual stress of substrate without film isn't affected by DCT. However, as shows in Table 2, residual stress of two groups of substrate after deposition respectively are $-336.52 \mathrm{MPa},-423.36 \mathrm{MPa}$. It illustrates that there is some different interaction between films and various treatment substrate, the substrate with DCT after deposition shows greater residual compressive stress. In general, the increase of hardness, strength and surface residual compressive stress is beneficial to improvement of load-bearing capacity, which can inhibit generation and propagate of cracks in friction and wear, eventually exhibits predominant wear resistance. It also shows the important value of DCT in this study. 

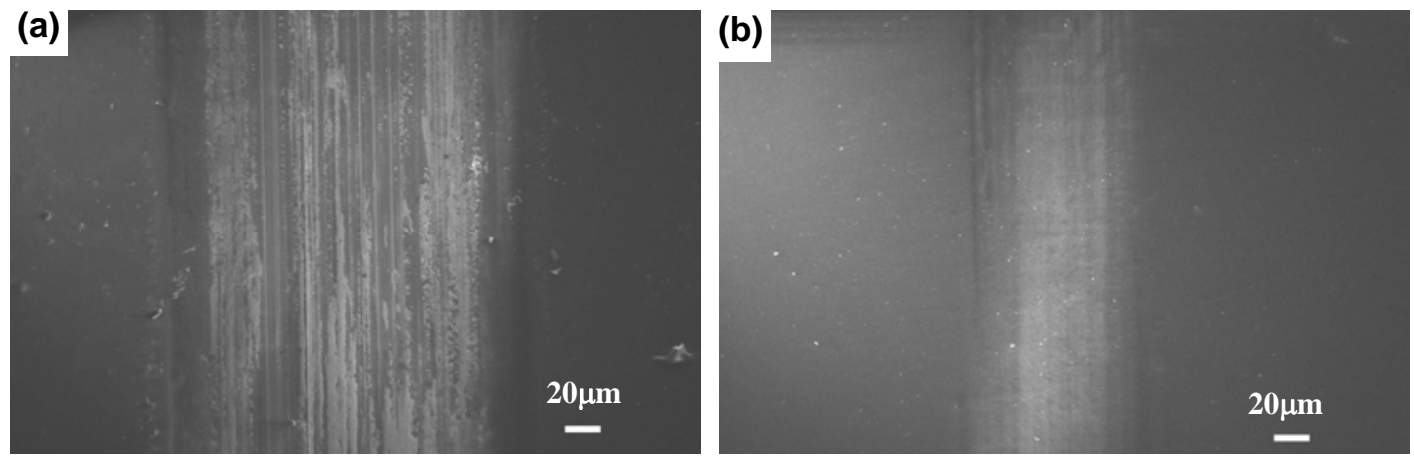

Fig.5 Wear tracks of DLC films (a) Untreated; (b) DCT
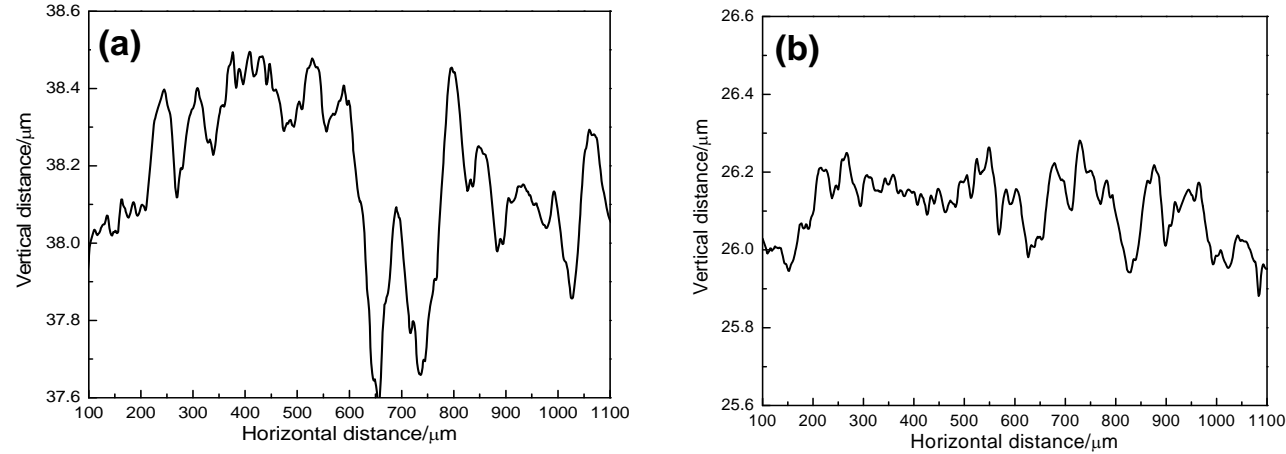

Fig.6 Wear scar's sectional contour of DLC films (a) Untreated; (b) DCT

Table 2 Surface residual stress of substrates before deposition, simulate deposition temperature, after deposition $[\mathrm{MPa}]$

\begin{tabular}{clll}
\hline Treatment & Before deposition & Simulate deposition temperature & After deposition \\
\hline Untreated & -369.20 & -290.84 & -336.52 \\
DCT & -446.02 & -291.16 & -423.36 \\
\hline
\end{tabular}

\section{Conclusions}

(1) The deep cryogenic treatment can eliminate retained austenite and increase uniform particle size of carbide percentage of W9 high-speed steel, so changed the surface morphology of substrate. Additionally, surface residual stress of substrate is improved remarkably.

(2) Film-substrate bonding strength of DLC films is improved by deep cryogenic pre-treatment of substrate. It is mainly because the increased grain boundary facilitate atoms diffusion within film-substrate interface, refined grains and new homogeneous carbides can enhance mechanical interlocking of film and substrate.

(3) Higher hardness, strength and added residual stress of substrate is beneficial to load-bearing capacity improvement, better deformation compatibility can inhibit generation and propagate of cracks and delamination of films during friction and wear. Eventually significantly improve the wear resistance of DLC films.

\section{Acknowledgements}

This work was financially supported by National Natural Science Fund of China (NSFC, Grant No.51271153).

\section{References}

[1] K. Bewillogua, D. Hofmann: Surface and Coatings Technology Vol. 242 (2014), p. 214-225.

[2] M. Masuko, T. Ono, S. Aoki, A. Suzuki and H. Ito: Tribology International Vol. 82 (2014), p. 350-357. 
[3] A. Erdemir, C. Donnet: Journal of Physics D-Applied Physics Vol. 39 (2006), p. 311-327.

[4] B.C. Ramos, E. Saito, V.J. Trava-Airoldi, A.O. Lobo and F.R. Marciano: Surface and Coatings Technology Vol. 259 (2014), p. 732-736.

[5] Y.J. Won, H. Ki: Applied Surface Science Vol. 311 (2014), p. 775-779.

[6] R.J. Narayan: Diamond and Related Materials Vol. 14 (2005), p. 1319-1330.

[7] M.J. Dai, C.B. Wei, K.S. Zhou, M. Zhu, H.J. Hou, S.S. Lin and X. Tong: Transactions of Nonferrous Metals Society of China Vol. 25 (2015), p. 3002-3011.

[8] H. Miki, T. Takeno and T. Takagi: Thin Solid Film Vol. 516 (2008), p. 5414-5418.

[9] W. Yang, Y.C. Guo, D.P. Xu, J.H. Li, P. Wang, P.L. Ke and A.Y. Wang: Surface and Coatings Technology Vol. 261 (2015), p. 398-403.

[10] L. Qiang, K.X. Gao, L.F. Zhang, J. Wang, B. Zhang and J.Y. Zhang: Applied Surface Science Vol. 353 (2015), p. 522-529.

[11] A. Modabberas1, P. Kameli, M. Ranjbar, H. Salamati and R. Ashiri: Carbon Vol. 94 (2015), p. 485-493.

[12] M. Koneshlou, K.M. Asl and F. Khomamizadeh: Cryogenics Vol. 51 (2011), p. 55-61.

[13] A. Oppenkowskia, S. Weberb and W. Theisena: Journal of Materials Processing Technology Vol. 210 (2010), p. 1949-1955

[14] K. Amini, A. Akhbarizadeh and S. Javadpour: Vacuum Vol. 86 (2012), p. 1534-1540.

[15] I.S Cho, A. Amanov and J.D. Kim: Tribology International Vol. 81 (2015), p. 61-72.

[16] A. Guzanova, J. Brezinova, D. Draganovska and F. Jas: Journal of Adhesion Science and Technology Vol. 28 ( 2014), p. 1754-1771.

[17] W. Zhu, C.H. Ran, Y.D. Jin, C.Y. Nie and Z.L. Wang: Surface Technology Vol. 41 (2012), p. 7-10, (In Chinese).

[18] A. Usman, M.S. Rafique, M. Khaleeq-ur-Rahman, K. Siraj, S. Anjum, H. Latif, T.M. Khan and M. Mehmood: Materials Chemistry and Physics Vol. 126 (2011), p. 649-654.

[19] Y. Deng, C.Y. Nie, Y. Ding, L.D. Wei, X.G. Zhou and N. Li: Transaction of Materials and Heat Treatment Vol. 33 (2012), p. 106-111, (In Chinese).

[20] M.Y. Zhang, K. Yang, Z. Chen, Y.X. Wang and J.Z. Zhang: Rare Metal Materials and Engineering, Vol. 42 (2013), p. 1531-1535, (In Chinese).

[21] G. Pagnoux, S. Fouvry, M. Peigney, B. Delattre and G. Mermaz-Rollet: Wear Vol. 330 (2015), p. 380-389. 